CIGS The Canon Institute for Global Studies

CIGS Working Paper Series No. 15-003E

\title{
Do Credit Market Imperfections Justify a Central Bank's Response to Asset Price Fluctuations?
}

\author{
Kengo Nutahara \\ Senshu University \\ The Canon Institute for Global Studies
}

September 2015

※Opinions expressed or implied in the CIGS Working Paper Series are solely those of the author, and do not necessarily represent the views of the CIGS or its sponsor.

※ CIGS Working Paper Series is circulated in order to stimulate lively discussion and comments.

※Copyright belongs to the author(s) of each paper unless stated otherwise.

General Incorporated Foundation

The Canon Institute for Global Studies

一般財団法人 キヤノングローバル戦略研究所

Phone: +81-3-6213-0550 http://www.canon-igs.org 


\title{
Do Credit Market Imperfections Justify a Central Bank's Response to Asset Price Fluctuations? *
}

\author{
Kengo Nutahara ${ }^{\dagger}$ \\ Senshu University \\ The Canon Institute for Global Studies
}

September 16, 2015

${ }^{*}$ This work is forthcoming in Journal of Economic Dynamics and Control. The author would like to thank Naohito Abe, Hiroki Arato, Takeo Hori, Masaru Inaba, Takashi Kano, Ryo Kato, Keiichiro Kobayashi, Kiminori Matsuyama, Keisuke Otsu, Morten Ravn, Katsuyuki Shibayama, Etsuro Shioji, Daichi Shirai, and seminar participants at University of Kent, Aoyama Gakuin University, Bank of Japan, Hitotsubashi University, the 2012 Meeting of the Royal Economic Society, the 2012 European Meeting of the Econometric Society, the 2012 Fall Meeting of the Japanese Economic Association, the 2014 Macro, Money, and Finance Conference, and the 2015 Singapore Economic Review Conference for their helpful comments. Ichiro Muto, the discussant at the 2012 Fall Meeting of the Japanese Economic Association, is especially aknowledged for his valuable comments and suggestions. The author is also grateful to James Bullard (Editor) and an anomynous referee for helpful comments. Of course, all errors are author's own.

${ }^{\dagger}$ E-mail: nutti@isc.senshu-u.ac.jp 


\begin{abstract}
Do credit market imperfections justify a central bank's response to asset price fluctuations? This study addresses this question from the perspective of equilibrium determinacy. In the model we use, prices are sticky and the working capital of firms is subject to asset values because of a lack of commitment. If credit market imperfections exist to a small degree, the Taylor principle is a necessary and sufficient condition for equilibrium determinacy, and monetary policy response to asset price fluctuations is good from the perspective of equilibrium determinacy. However, if credit market imperfections exist to a large degree such that the collateral constraint is binding, then the Taylor principle no longer guarantees equilibrium determinacy, and monetary policy response to asset price fluctuations becomes a source of equilibrium indeterminacy. We find that the existence of credit market imperfections makes it unsuitable to initiate a monetary policy response to deal with asset price fluctuations. We also find that reductions in credit market imperfections can enlarge the indeterminacy region of the model parameters.
\end{abstract}

Keywords: asset prices; credit market imperfections; collateral constraints; equilibrium indeterminacy; monetary policy; sticky prices; Taylor principle

JEL classification: E32; E44; E52 


\section{Introduction}

A classical topic in the context of monetary policy is a central bank's response to asset price fluctuations. The boom in Japan's economy during the late 1980s and its long stagnation during the 1990s and the recent economic boom and bust in the U.S. seem to imply that a central bank should respond to asset price fluctuations. It is often said that credit market imperfections play an important role in the boom-bust periods. In this scenario, should a central bank respond to asset price fluctuations and do credit market imperfections justify such a response?

In this study, we address this question from the perspective of equilibrium determinacy. Following the standard Calvo-type setting, prices are sticky in our model. We also assume that the working capital of firms is subject to asset values because of a lack of commitment. In cases where the collateral constraint never binds, the Taylor principle guarantees equilibrium determinacy and a positive response of monetary policy to asset price fluctuations increases the determinacy region of the parameters. In contrast, if the collateral constraint binds deeply, the properties of the determinacy regions completely differ. We find that the Taylor principle no longer guarantees equilibrium determinacy and that monetary policy response to asset price fluctuations is a source of equilibrium indeterminacy. We show that both the sufficiently positive and negative sensitivities of monetary policy are sources of equilibrium indeterminacy, while a slightly positive or negative response of monetary policy to asset price fluctuations might increase the determinacy region. Our results imply that the existence of credit market imperfections makes it unsuitable to initiate a monetary policy response to deal with asset price fluctuations.

We also investigate the relationship between the degree of credit market imperfections and the determinacy region. We find that reductions in credit market imperfections can sometimes reduce the determinacy region of model parameters. While it is intuitive that reductions in credit market imperfections have positive effects, our result shows that 
this simple intuition is not correct from the perspective of equilibrium determinacy.

This is because the binding collateral constraint changes the relationship between inflation and the asset price. In our model, if the credit market imperfection is small and the collateral constraint is not binding, inflation and the asset price move in the same direction. However, under the binding collateral constraint, these two variables move in opposite directions. Moreover, there exists a case where a reduction in credit market imperfection strengthens this negative relation between inflation and the asset price.

Many studies on monetary policy and asset prices deal with these topics from the welfare perspective. Bernanke and Gertler (2001) and Gilchrist and Leahy (2002) find that responding to asset price fluctuations is not important. Iacoviello (2005) shows that monetary policy response to asset price fluctuations generates welfare gain. Faia and Monacelli (2007) find that monetary policy should negatively respond to asset price fluctuations. In this study, however, we discuss this question from the perspective of equilibrium indeterminacy.

This study is closely related to Carlstrom and Fuerst (2007) and Nutahara (2014) that also focus on the relationship between monetary policy responds to asset prices and equilibrium indeterminacy. However, in their model, there is no credit market imperfection. We show that, in our model, monetary policy response to asset price fluctuations is a source of equilibrium indeterminacy in an economy with credit market imperfections, while it is a source of equilibrium determinacy if there is no credit market imperfection.

Collateral constraints are often employed to explain the observed facts of business cycles in modern macroeconomics. Bernanke, Gertler, and Gilchrist (1999), Kiyotaki and Moore (1997), and Liu, Wand, and Zha (2013) show that collateral constraints amplify shock effects. Carlstrom and Fuerst (1997, 1998) show that collateral constraints generate hump-shaped responses to shocks. Kobayashi, Nakajima, and Inaba (2012) show that a model with collateral constraints generates comovements of output, consumption, labor, and investment to news shocks. Monacelli (2009) shows that a 
model with collateral constraints accounts for sectoral comovements to monetary policy shocks. Given this information, analyses of a model with credit market imperfections would be important.

Recent studies focus on the financial frictions as an important mechanism for equilibrium indeterminacy. The present paper is also related to Harrison and Weder's (2013) study. They investigate equilibrium indeterminacy in a real model with collateral constraints and increasing returns to scale. In this study, we consider equilibrium indeterminacy in a monetary model with collateral constraints and constant returns to scale. Liu and Wang (2014) and Benhabib and Wang (2014) are also closely related to our paper since financial friction causes equilibrium indeterminacy in the non-monetary and constant returns to scale economies.

The rest of this paper is organized as follows. In Section 2, we introduce our model in which prices are sticky and the working capital is subject to asset values because of a lack of commitment. In Section 3, we investigate the equilibrium determinacy of the model and present the main results. In Section 4, we verify the robustness of our results. Finally, in Section 5, we draw conclusions.

\section{The model}

\subsection{Households: workers and managers}

Households consist of workers and managers. They hold as assets $B_{t-1}$, one-period nominal bonds that pay $R_{t-1}$ gross interest rate, and $N_{t-1}$, shares of the stock of retailers that sell at price $Q_{t}$ and pay dividend $D_{t}$.

The utility function is

$$
U\left(C_{t}, H_{t}\right)=\frac{C_{t}^{1-\sigma}}{1-\sigma}-\zeta \frac{H_{t}^{1+\gamma}}{1+\gamma}
$$

where $\sigma>0, \gamma>0, \zeta>0, C_{t}$ denotes consumption, and $H_{t}$ denotes labor supply. 
At the beginning of each period, a household is divided into a worker and a manager. A worker supplies labor $H_{t}$ and earns wage income $P_{t} W_{t} H_{t}$, where $P_{t}$ denotes the aggregate price level. A manager produces homogenous goods. The production function of managers is

$$
Y_{t}=K_{t}^{\alpha} L_{t}^{1-\alpha}
$$

where $0<\alpha<1, Y_{t}$ denotes output, $K_{t}$ denotes capital stock, and $L_{t}$ denotes labor demand.

We assume that managers have to pay wages to workers in advance and that they borrow working capital from banks. Banks can issue banknotes that can be circulated in the economy as payment instruments during a period. Let $N_{t}$ be the amount that managers borrow. Then,

$$
P_{t} W_{t} L_{t} \leq N_{t}
$$

Managers cannot commit to repay the debt fully. Then, their borrowing is subject to their collateral:

$$
N_{t} \leq \varphi P_{t} Q_{t} K_{t},
$$

where $0<\varphi \leq 1 .^{1}$ The debt is repaid at the end of the period. The gross interest rate of the managers' borrowing is one because banks are competitive and this borrowing is intratemporal. In order to consider a collateral constraint, we assume that a worker cannot supply to a manager from the same agent. Finally, the collateral constraint is

$$
P_{t} W_{t} L_{t} \leq \varphi P_{t} Q_{t} K_{t}
$$

The budget constraint is

$$
\begin{aligned}
& P_{t} C_{t}+P_{t} Q_{t} K_{t+1}+B_{t+1}+P_{t} W_{t} L_{t} \\
& \quad \leq P_{t} Z_{t} Y_{t}+P_{t} W_{t} H_{t}+P_{t} Q_{t} K_{t}+R_{t-1} B_{t},
\end{aligned}
$$

\footnotetext{
${ }^{1} \mathrm{~A}$ similar setting of credit market imperfections is employed by Harrison and Weder (2012), Kobayashi, Nakajima, and Inaba (2012), and Mendoza (2010).
} 
where $B_{t}$ denotes the bond holding, $Z_{t}$ denotes the relative price of goods produced by managers ${ }^{2}$, and $X_{t}$ denotes monetary injection.

The first-order conditions are as follows:

$$
\begin{aligned}
& \zeta C_{t}^{\sigma} H_{t}^{\gamma}=W_{t}, \\
& C_{t}^{-\sigma}=\beta C_{t+1}^{-\sigma} \frac{R_{t}}{\Pi_{t+1}}, \\
& C_{t}^{-\sigma} Q_{t}=\beta C_{t+1}^{-\sigma}\left[Q_{t+1}\left(1+\varphi \Theta_{t+1}\right)+\alpha Z_{t+1} \frac{Y_{t+1}}{K_{t+1}}\right], \\
& W_{t}\left(1+\Theta_{t}\right)=(1-\alpha) Z_{t} \frac{Y_{t}}{L_{t}}, \\
& \left(W_{t} L_{t}-\varphi Q_{t} K_{t}\right) \Theta_{t}=0, \quad \Theta_{t} \geq 0,
\end{aligned}
$$

where $\Pi_{t+1} \equiv P_{t+1} / P_{t}$ and $\Theta_{t}$ denote the ratio of the Lagrange multiplier of the collateral constraint to that of the budget constraint, and it can be interpreted as the inefficiency of the collateral constraint. Equation (7) is the intratemporal optimization condition; (8) is the Euler equation of bond; (9) is the Euler equation of capital stock; (10) is the marginal productivity condition of labor; and (11) is the collateral constraint.

Equation (9) can be rewritten in the form of familiar equations on asset prices:

$$
Q_{t}=\left[Q_{t+1}\left(1+\varphi \Theta_{t+1}\right)+\alpha Z_{t+1} \frac{Y_{t+1}}{K_{t+1}}\right] \frac{\Pi_{t+1}}{R_{t}} .
$$

The current asset price is a discounted sum of the future asset price and return on capital. One departure from the standard model is the existence of $\Theta_{t}$, the Lagrange multiple of the collateral constraint, which can be interpreted as a premium on capital as a collateral.

\subsection{Retailers}

We assume the existence of monopolistically competitive retailers, as in the study by Bernanke, Gertler, and Gilchrist (1999).

\footnotetext{
${ }^{2} Z_{t}$ is also interpreted as the real marginal cost of retailers.
} 
Retailers buy goods at price $P_{t} Z_{t}$ from managers, produce differentiated goods using a linear technology, and set prices. The price can be re-optimized at period $t$ only with probability $1-\kappa$. Under this standard Calvo-type sticky-price setting, as shown by Yun (1996), the New Keynesian Phillips curve is

$$
\pi_{t}=\lambda z_{t}+\beta \pi_{t+1}
$$

where

$$
\lambda \equiv \frac{(1-\kappa)(1-\kappa \beta)}{\kappa}
$$

and the lowercased letters denote log-deviations from the steady state.

\subsection{Monetary policy, market clearing conditions, and equilibrium}

We assume that the monetary authority follows a modified Taylor rule:

$$
r_{t}=\tau_{\pi} \pi_{t}+\tau_{k} q_{t}
$$

where $r_{t}$ denotes the log-deviation of the nominal interest rate, $R_{t}$, from a steady state. The parameters $\tau_{\pi}$ and $\tau_{k}$ denote the central bank's response to inflation and asset price fluctuations. In this study, we focus on the case of $\tau_{\pi}>0$ and $\tau_{k} \geq 0$.

For analytical simplicity, we assume that the total supply of capital stock is fixed and normalized to be one, that is,

$$
K_{t}=1
$$

Since there is no investment expenditure, the clearing condition of the goods market is

$$
Y_{t}=C_{t}
$$

At a symmetric equilibrium, the labor market clearing condition is

$$
H_{t}=L_{t} .
$$


In the model, there is no heterogeneity of households and the total supply of bonds is zero, that is,

$$
B_{t}=0 \text {. }
$$

Before proceeding to the main analysis, we investigate the condition for the binding collateral constraint. The following condition is necessary and sufficient for a binding collateral constraint at a steady state.

Proposition 1. A collateral constraint (5) is binding at a steady state if and only if

$$
\varphi<\varphi^{\max } \equiv \frac{(1-\alpha)(1-\beta)}{\alpha \beta} .
$$

Proof. See Appendix B.

\section{Main results}

\subsection{A sticky-price economy where the collateral constraint never binds}

First, consider a case where the collateral constraint never binds. It is convenient to loglinearize our equilibrium system for the analyses. The linearized equilibrium system is reduced to the following matrix form:

$$
\left[\begin{array}{c}
\pi_{t} \\
z_{t} \\
q_{t}
\end{array}\right]=\underbrace{\left[\begin{array}{ccc}
\tau_{\pi} & \chi & \tau_{k} \\
\tau_{\pi} & 0 & 1+\tau_{k} \\
1 & -\lambda & 0
\end{array}\right]^{-1}\left[\begin{array}{ccc}
1 & \chi & 0 \\
1 & (1-\beta) B & \beta \\
\beta & 0 & 0
\end{array}\right]}_{\boldsymbol{G}}\left[\begin{array}{l}
\pi_{t+1} \\
z_{t+1} \\
q_{t+1}
\end{array}\right],
$$

where

$$
\chi \equiv \frac{\sigma(1-\alpha)}{\sigma(1-\alpha)+\alpha+\gamma}
$$


and

$$
B \equiv \frac{\sigma(1-\alpha)+1+\gamma}{\sigma(1-\alpha)+\alpha+\gamma}
$$

Let $T, M$, and $D$ denote the trace, the sum of the principal minors of order 2 , and the determinant of $\boldsymbol{G}$, respectively. They are given by

$$
\begin{aligned}
& T=\frac{1}{\lambda \tau_{\pi}+\chi\left(1+\tau_{k}\right)}\left\{\chi(1+2 \beta)+\lambda+\lambda \beta \tau_{\pi}+[\chi(1+\beta)-B(1-\beta)] \tau_{k}\right\}, \\
& M=\frac{1}{\lambda \tau_{\pi}+\chi\left(1+\tau_{k}\right)}\left\{\lambda(2+\beta)+\lambda+[\chi-B(1-\beta)] \tau_{k}\right\}, \\
& D=\frac{\chi \beta^{2}}{\lambda \tau_{\pi}+\chi\left(1+\tau_{k}\right)} .
\end{aligned}
$$

The characteristic equation is

$$
F(x)=-x^{3}+T x^{2}-M x+D,
$$

and all roots should be within the unit circle for equilibrium determinacy. Brooks (2004) shows that the necessary and sufficient conditions of this first-order, three-dimensional discrete system are $|D|<1,|T+M|<M+1$, and $D^{2}-T D+M<1$.

In this case, the following proposition holds. ${ }^{3}$

Proposition 2. Assume that (i) $\beta>\frac{1+\gamma}{\sigma(1-\alpha)+1+\gamma}$ and (ii) the collateral constraint never binds. Then, a necessary and sufficient condition for equilibrium determinacy is

$$
\left(\tau_{\pi}-1\right) \lambda+\tau_{k} B(1-\beta)>0
$$

Proof. We employ the conditions in Brooks' (2004) study. $|D|<1$ holds if $\tau_{\pi}$ and $\tau_{k}$ are nonnegative. Since $\beta>\frac{1+\gamma}{\sigma(1-\alpha)+1+\gamma}$ implies $\chi-B(1-\beta)>0, T>0$ and $D>0$. Then,

\footnotetext{
${ }^{3}$ The similar model is considered by Nutahara (2014). Nutahara (2014) provides another proof to a similar proposition. He considers monetary policy response to asset price and finds the importance of the type of assets for equilibrium determinacy in a sticky-price model where the credit market is perfect.
} 
$T+D>0$, and $|T+D|<M+1$ implies $\left(\tau_{\pi}-1\right) \lambda+\tau_{k} B(1-\beta)$. Finally, $D^{2}-T D+M<1$ and $\tau_{\pi}>0$ imply that

$$
\tau_{\pi}>-\frac{\chi(1-\beta)+B \beta(1-\beta)}{\lambda} \tau_{k}+\beta-\frac{\chi(1+\beta)(1-\beta)^{2}}{\lambda}
$$

and it is easily shown that it also holds if $\left(\tau_{\pi}-1\right) \lambda+\tau_{k} B(1-\beta)>0$ and $\beta>\frac{1+\gamma}{\sigma(1-\alpha)+1+\gamma}$.

Proposition 2 implies that a positive monetary policy response to asset prices is a source of equilibrium determinacy, as follows.

Remark 1. Even if $\tau_{\pi}<1$, equilibrium determinacy is guaranteed if

$$
\tau_{k}>\frac{\left(1-\tau_{\pi}\right) \lambda}{B(1-\beta)}
$$

in a sticky-price economy where the collateral constraint never binds.

As shown by Nutahara (2014), the Taylor principle - a permanent increase in the inflation rate leads to a more than proportionate increase in the nominal interest rate-is a necessary and sufficient condition for equilibrium determinacy in the model without the collateral constraint.

A one-percentage point permanent increase in the inflation rate causes the real marginal cost to increase by $(1-\beta) / \lambda$ by the Phillips curve. This increases the rental rate of capital and capital prices by $B(1-\beta) / \lambda$ since the Euler equation (??) becomes

$$
q_{t}=\beta q_{t+1}+(1-\beta) B z_{t+1}+\left(\pi_{t+1}-r_{t}\right)
$$

Thus, the overall effect on nominal interest rate is

$$
\tau_{\pi}+\tau_{k} \frac{B(1-\beta)}{\lambda}
$$

The Taylor principle is consistent with that (23) is greater than one, and it is the same as the condition of Proposition 2.

Finally, monetary policy responding to capital prices is helpful for equilibrium determinacy since it implicitly strengthens the overall reactions to inflation. 


\subsection{A sticky-price economy with the binding collateral constraint}

Here, we focus on a case where a collateral constraint is deeply binding.

The equilibrium system is reduced to the following matrix form:

$$
\left[\begin{array}{c}
\pi_{t} \\
z_{t} \\
q_{t}
\end{array}\right]=\underbrace{\left[\begin{array}{ccc}
\tau_{\pi} & 0 & \Phi_{1}+\tau_{k} \\
\tau_{\pi} & 0 & 1+\tau_{k} \\
1 & -\lambda & 0
\end{array}\right]^{-1}\left[\begin{array}{ccc}
1 & 0 & \Phi_{1} \\
1 & 1-\beta(1-\varphi) & \Phi_{2} \\
\beta & 0 & 0
\end{array}\right]}_{\boldsymbol{G}}\left[\begin{array}{c}
\pi_{t+1} \\
z_{t+1} \\
q_{t+1}
\end{array}\right],
$$

where

$$
\begin{aligned}
& \Phi_{1} \equiv \frac{\sigma}{\sigma+\frac{1+\gamma}{1-\alpha}}, \\
& \Phi_{2} \equiv \frac{\left[\sigma+\frac{1+\gamma}{1-\alpha}-1\right] \beta(1-\varphi)+1}{\sigma+\frac{1+\gamma}{1-\alpha}} .
\end{aligned}
$$

It is obvious that $0<\Phi_{1}<1$ and $\Phi_{2}>0$. It is shown that $\Phi_{2}<1$ since

$$
1-\Phi_{2}=[1-\beta(1-\varphi)]\left(1-\frac{1}{\sigma+\frac{1+\gamma}{1-\alpha}}\right)>0 .
$$

In this case, the characteristic equation is

$$
F(x)=-x^{3}+T x^{2}-M x+D,
$$

where

$$
\begin{aligned}
& T=\frac{1}{\tau_{\pi} \lambda\left(\Phi_{1}-1\right)}\left\{\tau_{\pi} \lambda\left(\Phi_{1}-\Phi_{2}\right)+\lambda\left(\Phi_{1}-1\right)+\left(\tau_{k}+\Phi_{1}\right)[1-\beta(1-\varphi)]\right\}, \\
& M=\frac{1}{\tau_{\pi} \lambda\left(\Phi_{1}-1\right)}\left\{\lambda\left(\Phi_{1}-\Phi_{2}\right)+\Phi_{1}(1+\beta)[1-\beta(1-\varphi)]+\tau_{k} \beta[1-\beta(1-\varphi)]\right\}, \\
& D=\frac{1}{\tau_{\pi} \lambda\left(\Phi_{1}-1\right)}\left\{\beta \Phi_{1}[1-\beta(1-\varphi)]\right\} .
\end{aligned}
$$

A necessary and sufficient condition for equilibrium determinacy is as follows. 
Proposition 3. Assume that (20) and that the collateral constraint is always binding. A necessary and sufficient condition for equilibrium determinacy is

$$
\begin{aligned}
& \text { (A) } \tau_{\pi}>\tau_{\pi}^{\min } \equiv \frac{\beta \Phi_{1}[1-\beta(1-\varphi)]}{\lambda\left(1-\Phi_{1}\right)}, \\
& \text { (B) } \tau_{k}^{\min }<\tau_{k}<\tau_{k}^{\max } \\
& \text { (C) } D^{2}-T D+M<1,
\end{aligned}
$$

where

$$
\begin{aligned}
\tau_{k}^{\min } & \equiv-\left(\tau_{\pi}-1\right) \frac{\lambda\left(1-\Phi_{2}\right)}{(1-\beta)[1-\beta(1-\varphi)]}, \\
\tau_{k}^{\max } & \equiv\left(\tau_{\pi}+1\right) \frac{\lambda\left(1-2 \Phi_{1}+\Phi_{2}\right)}{(1+\beta)[1-\beta(1-\varphi)]}-2 \Phi_{2} .
\end{aligned}
$$

Proof. The conditions stipulated by Brooks (2004) are employed. The condition $|D|<1$ is equivalent to (A). The condition $|T+D|<M+1$ is equivalent to (B). $T+D\rangle 0$ if $\tau_{k}<\tau_{k}^{\text {thres }}$, where

$$
\tau_{k}^{\text {thres }} \equiv \frac{\lambda\left(\Phi_{2}-\Phi_{1}\right)}{1-\beta(1-\varphi)} \tau_{\pi}+\frac{1}{1-\beta(1-\varphi)}\left\{\lambda\left(1-\Phi_{1}\right)+\Phi_{1}\left[1-\beta^{2}+\beta \varphi(1+\varphi)\right]\right\}
$$

If $T+D>0,|T+D|<M+1$ implies that $\tau_{k}^{\min }<\tau_{k}<\tau_{k}^{\text {thres }}$. If $\tau_{k}^{\text {thres }} \leq \tau_{k}, T+D \leq 0$ and $|T+D|<M+1$ implies $\tau_{k}^{\text {thres }} \leq \tau_{k}<\tau_{k}^{\max }$.

The Taylor principle and equilibrium indeterminacy: Under some conditions, the threshold $\tau_{\pi}^{\min }$ in Proposition 3 is greater than 1. For example, if $\sigma=1, \gamma=0, \alpha=0.3$, $\beta=.99, \varphi=0.02$, and $\lambda=0.019$, then $\tau_{\pi}^{\min }$ is about 1.09. If $\tau_{k}=0$, the Taylor principle implies that $\tau_{\pi}>1$. However, if $1<\tau_{\pi}<\tau_{\pi}^{\min }$, then equilibrium indeterminacy arises. Therefore, the Taylor principle does not guarantee equilibrium determinacy.

Remark 2. The Taylor principle does not guarantee equilibrium determinacy in a stickyprice economy with a binding collateral constraint. 
Monetary policy and equilibrium indeterminacy: Next, consider the relationship between equilibrium indeterminacy and the monetary policy response to asset price fluctuations.

Condition (B) implies that there is an interval of $\tau_{k}$ for equilibrium determinacy. The existence of the lower bound, $\tau_{k}^{\min }$, is not so important since $\tau_{k}^{\min }<0$ if $\tau_{\pi}>1$. The existence of the upper bound, $\tau_{k}^{\max }$, is important, and equilibrium indeterminacy arises if a central bank is sufficiently sensitive to asset price fluctuations.

Remark 3. If $\tau_{k}>\tau_{k}^{\max }$, equilibrium indeterminacy arises.

To investigate the determinacy region of the model, we conduct numerical analyses. We employ the following parameter values in line with those used in the literature. The discount factor, $\beta$, is 0.99 . The utility function is made up of log consumption and indivisible labor $(\sigma=1$ and $\gamma=0)$. The cost weight of capital in the production function, $\alpha$, is 0.3 . The parameter of the New Keynesian Phillips curve, $\lambda$, is 0.019 . The steadystate real marginal cost, $Z$, is 0.85 . The parameter of credit market imperfections, $\varphi$, is 0.02 for the deeply binding collateral constraint at a steady state. Under these parameter values, we calculate the eigenvalues of $\boldsymbol{G}$ in equation (24) to check equilibrium determinacy.

Figure 1 shows the determinacy region in the $\left(\tau_{k}, \tau_{\pi}\right)$ plane. In the region with red diamonds, equilibrium is determinate. Equilibrium indeterminacy arises in other regions. The vertical axis denotes the central bank's response to inflation $\tau_{\pi}$. The horizontal axis denotes the central bank's response to the asset price $\tau_{k}$.

\section{[Insert Figure 1]}

As in Remark 3, the sufficient sensitivity of monetary policy is a source of equilibrium indeterminacy. In Figure 1, the positive slope of the determinacy region reflects $\tau_{k}^{\max }$, and the negative slope reflects $(\mathrm{C})$ in Proposition 3. Note that the determinacy 
region of $\tau_{\pi}$ is the largest when $\tau_{k}$ is slightly negative. However, the sign of the determinacy region's peak $\tau_{k}$ might be positive. Figure 1 shows the determinacy region if $\sigma=\gamma=2$. Figure 2 shows that the determinacy region is shaped by three lines: the positive slope line of $\tau_{k}^{\max }$, the negative slope line of $\tau_{k}^{\min }$, and (C) in Proposition 3. The determinacy region of $\tau_{\pi}$ is the largest when $\tau_{k}$ is positive.

\section{[Insert Figure 2]}

Finally, we find that the sufficient sensitivity of monetary policy is a source of equilibrium indeterminacy in the economy with the binding collateral constraint, while a positive monetary policy response is a source of equilibrium determinacy in the economy where the collateral constraint never binds. This result implies that the existence of credit market imperfections makes it unsuitable to initiate a monetary policy response to deal with asset price fluctuations.

Why does the effect of monetary policy response to asset prices depend on whether the collateral constraint is binding? The key is the relationship between inflation and the asset price. In the case of a non-binding collateral constraint, inflation and the asset price move in the same direction, and monetary policy response to asset prices strengthens the overall reaction to inflation. In the case of the binding collateral constraint, there exists a pressure that inflation and the asset price move in opposite directions. The intuition is as follows. Suppose that the asset price increases. This relaxes the collateral constraint, and the Lagrange multiplier of the constraint $\Theta_{t}$ tends to decrease. This implies a decrease in the real marginal $\operatorname{cost} Z_{t}$ since it is given by

$$
Z_{t}=\frac{W_{t} L_{t}+R_{t}^{K} K_{t}}{Y_{t}}+\Theta_{t} \frac{W_{t} L_{t}}{Y_{t}}
$$

where $R_{t}^{K}=\alpha Z_{t} \frac{Y_{t}}{K_{t}}$ is the shadow rental price of capital. If the real marginal cost decreases, price-setting firms lower their prices and the aggregate inflation rate decreases. As a result, there exists a possibility that the asset price and inflation move in opposite directions if the collateral constraint is binding. Therefore, including the asset price term 
in the Taylor rule weakens the overall reaction to inflation, and such inclusion is a source of equilibrium indeterminacy.

Credit market imperfections and equilibrium indeterminacy: How do credit market imperfections affect equilibrium determinacy? As $\tau_{k}^{\max }$ depends on $\varphi$, such imperfections would have some effects on equilibrium determinacy. To address this question, we employ numerical analyses.

First, consider a standard monetary policy that asset prices are not targeted: $\tau_{k}=0$. Figure 3 shows the determinacy region in the $\left(\tau_{\pi}, \varphi\right)$ plane. As in Figure 1, the region with red diamonds denotes equilibrium determinacy and the others indicate equilibrium indeterminacy. The vertical axis denotes the collateral constraint parameter $\varphi$. The horizontal axis denotes the central bank's response to inflation $\tau_{\pi}$. Except for $\tau_{k}=$ 0, other parameters are the same as those in Figure 1. We consider cases where $\varphi \in$ $\left[\varphi^{\max } / 2, \varphi^{\max }\right]$.

\section{[Insert Figure 3]}

Figure 3 shows that reductions in credit market imperfections, or increases in $\varphi$, have nonlinear effects on the determinacy region. If $\varphi$ is larger than 0.018 , an increase in $\varphi$ reduces the determinacy region of $\tau_{\pi}$, and higher values of $\tau_{\pi}$ are necessary for equilibrium determinacy. This is affected by the condition $\tau_{k}<\tau_{k}^{\max }$ of Proposition 3 . If $\varphi$ is smaller than about 0.017 , an increase in $\varphi$ does not affect the determinacy region of $\tau_{\pi}$. This is because $\tau_{k}>\tau_{k}^{\mathrm{min}}$ implies $\tau_{\pi}>1$ if $\tau_{k}=0$.

If $\varphi$ is large enough so that the collateral constraint never binds, $\tau_{\pi}>1$ guarantees equilibrium determinacy as in Proposition 2. Then, sufficient reductions in credit market imperfections might increase the determinacy region. Generally, however, there is a case where reductions in credit market imperfections reduce the determinacy regions of $\tau_{\pi}$, as shown in Figure 3. Then, a small reduction in credit market imperfection might require a stronger stance to inflation for determinacy. 
Next, we focus on the case where $\tau_{k}$ is positive. Figure 4 shows the determinacy region in the $\left(\tau_{k}, \varphi\right)$ plane. The vertical axis denotes the collateral constraint parameter $\varphi$. The horizontal axis denotes the central bank's response to the asset price $\tau_{k}$. We set the parameter of the central bank's response to inflation, $\tau_{\pi}$, as 1.5 ; the others are the same as those in the previous analysis. Figure 4 shows that reductions in credit market imperfections reduce the determinacy region of $\tau_{k}$.

\section{[Insert Figure 4]}

This result can be interpreted by the relationship between inflation and the asset price. As in the explanation on the intuition behind Figures 1 and 2, if the collateral constraint is binding, there is a possibility that inflation and the asset price move in opposite directions. A reduction in credit market imperfections might strengthen this relationship. The degree of credit market imperfection, $\varphi$, is in the collateral constraint, and then, an increase in $\varphi$ strengthens effects of an increase in the asset price to relax the constraint and to decrease the real marginal cost and inflation.

Finally, we find there is a case where reductions in credit market imperfections reduce the determinacy region of $\tau_{\pi}$ and $\tau_{k}$. While it is intuitive that reductions in credit market imperfections have positive effects on the economy, our result shows that this simple intuition is not correct from the perspective of equilibrium determinacy.

\section{Robustness: Endogenous capital stock}

For simplicity of the analyses, we have so far assumed that the total supply of capital stock is fixed. In this subsection, however, we consider a case where capital evolves over time. 
As a result, the households' budget constraint (6) becomes

$$
\begin{aligned}
P_{t} C_{t}+ & P_{t} I_{t}+M_{t+1}+B_{t+1}+P_{t} Q_{t} K_{t+1}+P_{t} W_{t} L_{t} \\
& \leq P_{t} Z_{t} Y_{t}+P_{t} W_{t} H_{t}+M_{t}+R_{t-1} B_{t}+(1-\delta) P_{t} Q_{t} K_{t}+X_{t},
\end{aligned}
$$

where $I_{t}$ is the investment and $\delta \in(0,1)$ is the depreciation rate of capital.

We assume that the capital price varies since there is an adjustment cost of investment. The evolution of capital stock is

$$
K_{t+1}=(1-\delta) K_{t}+\Gamma\left(I_{t}\right)
$$

where $\Gamma(\cdot)$ is increasing and concave with $\Gamma(0)=0$. Following Carlstrom and Fuerst (2005), we specify the functional form of $\Gamma\left(I_{t}\right)$ as

$$
\Gamma\left(I_{t}\right) \equiv b I_{t}^{\eta}
$$

where $\eta$ is between 0 and 1 . The first-order condition for investment is

$$
Q_{t}=\frac{1}{\Gamma^{\prime}\left(I_{t}\right)}
$$

The parameter $b$ is chosen so that $Q_{t}=1$ in the steady state, its value in the economy with no adjustment cost. Then, $b=I^{1-\eta} / \eta$, where $I$ denotes a steady-state investment.

The resource constraint (17) is

$$
C_{t}+I_{t}=Y_{t}
$$

The following is a condition for the binding collateral constraint in this case.

Proposition 4. In an economy with a variation of capital stock, a collateral constraint (5) is binding at a steady state if and only if

$$
\varphi<\varphi_{K}^{\max } \equiv \frac{(1-\alpha)\left[\frac{1}{\beta}-1+\delta\right]}{\alpha} .
$$

Proof. See Appendix C. 
In this case, the equilibrium system consists of three jump variables and one state variable. We investigate the determinacy region by conducting numerical analyses. The depreciation rate of capital, $\delta$, is 0.025 , and the adjustment cost parameter, $\eta$, is 0.5 . The others are the same as those employed in Section 3.

If the collateral constraint never binds, this model is similar to that considered by Nutahara (2012). He shows that monetary policy response to capital prices is a source of equilibrium determinacy even if total capital stock is endogenous. Then, we focus on the case where the collateral constraint is binding.

Figure 5 is the analogue of Figure 1. In the region with red diamonds, equilibrium is determinate; equilibrium indeterminacy arises in other regions; and the horizontal axis denotes the central bank's response to the share price $\tau_{k}$. As in Figure 1, sufficient sensitivity of monetary policy to the capital prices is a source of equilibrium indeterminacy.

\section{[Insert Figure 5]}

Figure 6 is the analogue of Figure 3. The horizontal axis denotes the parameter of

credit market imperfections, $\varphi$. We consider cases where $\varphi \in\left[\varphi_{K}^{\max } / 5, \varphi_{K}^{\max }\right]$. The parameter values are the same as in Figure 3. Figure 7 is the analogue of Figure 4. The parameter values are the same as in Figure 4. Similar to Figures 3 and 4, Figures 6 and 7 indicate that reductions in credit market imperfections can reduce the determinacy regions of $\tau_{\pi}$ and $\tau_{k}$. Finally, our results in Section 3 are robust when capital stock varies over time.

[Insert Figures 6 and 7]

\section{Concluding remarks}

In this study, we investigated monetary policy response to asset price fluctuations in a monetary economy with credit market imperfections. This study was carried out from 
the perspective of equilibrium determinacy. In our model, the prices are sticky and the working capital of firms is subject to asset values because of a lack of commitment problem.

We found that the Taylor principle does not guarantee equilibrium determinacy if the collateral constraint is binding. We also found that (i) monetary policy response to asset price fluctuations is a source of equilibrium indeterminacy if the collateral constraint is binding, while it is helpful for equilibrium determinacy if the constraint is not binding, and that (ii) there exists a case where reductions in credit market imperfections can reduce the determinacy region of model parameters.

This is because the binding collateral constraint changes the relationship between inflation and the asset price. In our model, if the credit market imperfection is small and collateral constraint is not binding, inflation and the asset price move in the same direction. Contrary to this, under the binding collateral constraint, these two variables move in opposite directions. Moreover, there exists a case where a reduction in credit market imperfections strengthens this negative relation between inflation and the asset price.

Our results imply that a central bank should not respond to asset price fluctuations if the credit market is imperfect, and that reductions in credit market imperfections might not be good from the perspective of equilibrium determinacy. These counterintuitive implications would be important when we consider the relationship between monetary policy and asset prices. 


\section{Appendix A: Equilibrium System}

The equilibrium system of this economy is as follows:

$$
\begin{aligned}
& \zeta C_{t}^{\sigma} L_{t}^{\gamma}=W_{t}, \\
& C_{t}^{-\sigma}=\beta C_{t+1}^{-\sigma} \frac{R_{t}}{\Pi_{t+1}}, \\
& Q_{t}=\left[Q_{t+1}\left(1+\varphi \Theta_{t+1}\right)+\alpha Z_{t+1} Y_{t+1}\right] \frac{\Pi_{t+1}}{R_{t}}, \\
& W_{t}\left(1+\Theta_{t}\right)=(1-\alpha) Z_{t} \frac{Y_{t}}{L_{t}}, \\
& \left(W_{t} L_{t}-\varphi Q_{t}\right) \Theta_{t}=0, \quad \Theta_{t} \geq 0, \\
& Y_{t}=L_{t}^{1-\alpha}, \\
& Y_{t}=C_{t}, \\
& \pi_{t}=\lambda z_{t}+\beta \pi_{t+1}, \\
& r_{t}=\tau_{\pi} \pi_{t}+\tau_{q} q_{t} .
\end{aligned}
$$

Case where the collateral constraint never bind: In the case where the collateral constraint never binds, the linearized system becomes to the following:

$$
\begin{aligned}
& \sigma c_{t}+\gamma \ell_{t}=w_{t}, \\
& \sigma\left(c_{t+1}-c_{t}\right)=r_{t}-\pi_{t+1}, \\
& q_{t}=\beta q_{t+1}+(1-\beta)\left(z_{t+1}+c_{t+1}\right)+\left(\pi_{t+1}-r_{t}\right), \\
& c_{t}=(1-\alpha) \ell_{t}, \\
& z_{t}+c_{t}-\ell_{t}=w_{t}, \\
& \pi_{t}=\beta \pi_{t+1}+\lambda z_{t}, \\
& r_{t}=\tau_{\pi} \pi_{t}+\tau_{k} q_{t},
\end{aligned}
$$


where the lowercased letters denote log-deviations from the steady state. This is reduced to the following three-variable system:

$$
\left[\begin{array}{ccc}
1 & 0 & \Phi_{1} \\
1 & 1-\beta(1-\varphi) & \Phi_{2} \\
\beta & 0 & 0
\end{array}\right]\left[\begin{array}{c}
\pi_{t+1} \\
z_{t+1} \\
q_{t+1}
\end{array}\right]=\left[\begin{array}{ccc}
\tau_{\pi} & 0 & \Phi_{1}+\tau_{k} \\
\tau_{\pi} & 0 & 1+\tau_{k} \\
1 & -\lambda & 0
\end{array}\right]\left[\begin{array}{c}
\pi_{t} \\
z_{t} \\
q_{t}
\end{array}\right],
$$

where

$$
\begin{aligned}
& \Phi_{1} \equiv \frac{\sigma}{\sigma+\frac{1+\gamma}{1-\alpha}}, \\
& \Phi_{2} \equiv \frac{\left[\sigma+\frac{1+\gamma}{1-\alpha}-1\right] \beta(1-\varphi)+1}{\sigma+\frac{1+\gamma}{1-\alpha}} .
\end{aligned}
$$

Case where the collateral constraint is binding: In the case where the collateral constraint is binding, the linearized system is as follows:

$$
\begin{aligned}
& \sigma c_{t}+\gamma \ell_{t}=w_{t}, \\
& \sigma\left(c_{t+1}-c_{t}\right)=r_{t}-\pi_{t+1}, \\
& q_{t}=\beta(1+\varphi \Theta)\left[q_{t+1}+\frac{\varphi \Theta}{1+\varphi \Theta} \theta_{t+1}\right]+[1-\beta(1+\varphi \Theta)]\left(z_{t+1}+c_{t+1}\right)+\left(\pi_{t+1}-r_{t}\right), \\
& c_{t}=(1-\alpha) \ell_{t}, \\
& w_{t}+\ell_{t}=q_{t}, \\
& z_{t}+c_{t}-\ell_{t}=w_{t}+\frac{\Theta}{1+\Theta} \theta_{t}, \\
& \pi_{t}=\beta \pi_{t+1}+\lambda z_{t}, \\
& r_{t}=\tau_{\pi} \pi_{t}+\tau_{k} q_{t} .
\end{aligned}
$$

This system is reduced to the following three-variable system:

$$
\left[\begin{array}{ccc}
1 & 0 & \Phi_{1} \\
1 & 1-\beta(1-\varphi) & \Phi_{2} \\
\beta & 0 & 0
\end{array}\right]\left[\begin{array}{c}
\pi_{t+1} \\
z_{t+1} \\
q_{t+1}
\end{array}\right]=\left[\begin{array}{ccc}
\tau_{\pi} & 0 & \Phi_{1}+\tau_{k} \\
\tau_{\pi} & 0 & 1+\tau_{k} \\
1 & -\lambda & 0
\end{array}\right]\left[\begin{array}{c}
\pi_{t} \\
z_{t} \\
q_{t}
\end{array}\right]
$$


where

$$
\begin{aligned}
& \Phi_{1} \equiv \frac{\sigma}{\sigma+\frac{1+\gamma}{1-\alpha}}, \\
& \Phi_{2} \equiv \frac{\left[\sigma+\frac{1+\gamma}{1-\alpha}-1\right] \beta(1-\varphi)+1}{\sigma+\frac{1+\gamma}{1-\alpha}} .
\end{aligned}
$$

\section{Appendix B: Proof of Proposition 1}

Proof. By the steady-state equilibrium system, we obtain

$$
\begin{aligned}
& W=\zeta L^{\sigma(1-\alpha)+\gamma}, \\
& L=\frac{1}{\zeta}\left[\frac{1-\alpha}{1+\Theta} Z\right]^{1 /(\sigma(1-\alpha)+\gamma+\alpha)}, \\
& Q=\frac{\alpha Z}{\frac{1}{\beta}-(1+\varphi \Theta)}\left[\frac{1-\alpha}{1+\Theta} Z\right]^{(1-\alpha) /(\sigma(1-\alpha)+\gamma+\alpha)} .
\end{aligned}
$$

Inserting these into a collateral constraint, $W L=\varphi Q$, yields

$$
\Theta=\frac{(1-\alpha)(1-\beta)}{\beta \varphi}-\alpha,
$$

where $\Theta$ is greater than 0 if and only if $\varphi<\varphi^{\max }$. 


\section{Appendix C: Proof of Proposition 4}

Proof. The equilibrium system of the economy with a variation of capital stock is

$$
\begin{aligned}
& \zeta C_{t}^{\sigma} L_{t}^{\gamma}=W_{t}, \\
& C_{t}^{-\sigma}=\beta C_{t+1}^{-\sigma} \frac{R_{t}}{\Pi_{t+1}}, \\
& Q_{t}=\left[\left(1-\delta+\varphi \Theta_{t+1}\right) Q_{t+1}+\alpha Z_{t+1} \frac{Y_{t+1}}{K_{t+1}}\right] \frac{\Pi_{t+1}}{R_{t}} . \\
& W_{t}\left(1+\Theta_{t}\right)=(1-\alpha) Z_{t} \frac{Y_{t}}{L_{t}}, \\
& \left(W_{t} L_{t}-\varphi Q_{t} K_{t}\right) \Theta_{t}=0, \quad \Theta_{t} \geq 0, \\
& Y_{t}=K_{t}^{\alpha} L_{t}^{1-\alpha}, \\
& Q_{t}\left[\frac{I_{t}}{I_{s s}}\right]^{1-\gamma} \cdot \\
& Y_{t}=C_{t}+I_{t}, \\
& K_{t+1}=(1-\delta) K_{t}+\Gamma\left(I_{t}\right), \\
& \pi_{t}=\lambda z_{t}+\beta \pi_{t+1}, \\
& r_{t}=\tau_{\pi} \pi_{t}+\tau_{q} q_{t} .
\end{aligned}
$$

At a steady state, with $\Pi=L=1$ and $\Gamma\left(I_{t}\right) \equiv b I_{t}^{\eta}$, this system becomes

$$
\begin{aligned}
& R=\frac{1}{\beta}, \\
& 1=\beta\left[(1-\delta+\varphi \Theta)+\alpha Z \frac{Y}{K}\right] . \\
& W(1+\Theta)=(1-\alpha) Z Y, \\
& (W-\varphi K) \Theta=0, \quad \Theta \geq 0, \\
& Y=K^{\alpha}, \\
& Q=1 . \\
& Y=C+\eta \delta K .
\end{aligned}
$$


Since

$$
W=\frac{1-\alpha}{1+\Theta} Z K^{\alpha}, \quad \text { and } \quad K=\left[\frac{\alpha Z}{\frac{1}{\beta}-1+\delta-\varphi \Theta}\right]^{\frac{1}{1-\alpha}},
$$

the binding collateral constraint is

$$
\frac{1-\alpha}{1+\Theta}=\varphi \cdot \frac{\alpha}{\frac{1}{\beta}-1+\delta-\varphi \Theta}
$$

Then, the Lagrange multiplier of the collateral constraint $\Theta$ is

$$
\Theta=\frac{(1-\alpha)\left[\frac{1}{\beta}-1+\delta\right]}{\varphi}-\alpha
$$

Therefore, the collateral constraint is binding at a steady state if and only if

$$
\varphi<\frac{(1-\alpha)\left[\frac{1}{\beta}-1+\delta\right]}{\alpha}
$$

\section{References}

Benhabib, J., and P. Wang, 2013. Financial constraints, endogenous markups, and selffulfilling equilibria. J. Monet. Econ. 60(7), 789-805.

Bernanke, B., and M. Gertler, 2001, Should central banks respond to movements in asset prices? Am. Econ. Rev. 91(2), 253-257.

Bernanke, B., M. Gertler, and S. Gilchrist, 1999, The financial accelerator in a quantitative business cycle framework, in: J. Taylor and M. Woodford, eds., Handbook of Macroeconomics, Vol. 1C (North-Holland, Amsterdam) 1341-1393.

Brooks, B. P., 2004, Linear stability conditions for a first-order three-dimensional discrete dynamic, Applied Mathematics Letters 17, 463-66. 
Carlstrom, C. T., and T. S. Fuerst, 1997, Agency costs, net worth, and business fluctuations: A computable general equilibrium analysis, Am. Econ. Rev. 87, 893-910.

Carlstrom, C. T., and T. S. Fuerst, 1998, Agency costs and business cycles, Econ. Theory $12,583-597$.

Carlstrom, C. T., and T. S. Fuerst, 2005, Investment and interest rate policy: A discrete time analysis, J. Econ. Theory 123, 4-20.

Carlstrom, C. T., and T. S. Fuerst, 2007, Asset prices, nominal rigidities, and monetary policy, Rev. Econ. Dyn. 10, 256-275.

Faia, E., and T. Monacelli, 2007, Optimal interest rate rules, asset prices, and credit frictions, J. Econo. Dyn. Control 31, 3228-3254.

Gertler, M., and N. Kiyotaki, 2010, Financial intermediation and credit policy in business cycle analysis, in: B.M. Friedman and M. Woodford, eds., Handbook of Monetary Economics, Vol. 3A (North-Holland, Amsterdam) 547-599.

Gilchrist, S., and J. V. Leahy, 2002, Monetary policy and asset prices, J. Monet. Econ. 49(1), 75-97.

Harrison, S. G., and M. Weder, 2013, Sunspots and credit frictions, Macroecon. Dyn. 17(05), 1055-1069.

Iacoviello, M., 2005, House prices, borrowing constraints, and monetary policy in the business cycle, Am. Econ. Rev. 95(2), 739-764.

Kiyotaki, N., and J. Moore, 1997, Credit cycles, J. Polit. Economy 105(2), 211-248.

Kobayashi, K., T. Nakajima, and M. Inaba, 2012, Collateral constraint and news-driven cycles, Macroecon. Dyn. 16(5), 752-776. 
Liu, Z., and P. Wang. 2014. Credit constraints and self-fulfilling business cycles. Am. Econ. J.: Macroecon., 6(1): 32-69.

Liu, A., P. Wand, and T. Zha, 2013, Land- price dynamics and macroeconomic fluctuations, Econometrica 81(3), 1147-1184.

Mendoza, E.G., 2010, Sudden stops, financial crises and leverage, Am. Econ. Rev. 100(5), 1941-1966.

Monacelli, T., 2009, New Keynesian models, durable goods, and collateral constraints, J. Monet. Econ. 56, 242-254.

Nutahara, K., 2014, What asset prices should be targeted by a central bank? J. Money Credit Banking 46(4), 817-836.

Yun, T., 1996, Nominal price rigidity, money supply endogeneity, and business cycles. J. Monet. Econ. 37(2), 345-370. 
Figure 1: Effect of monetary policy on the determinacy region (1)

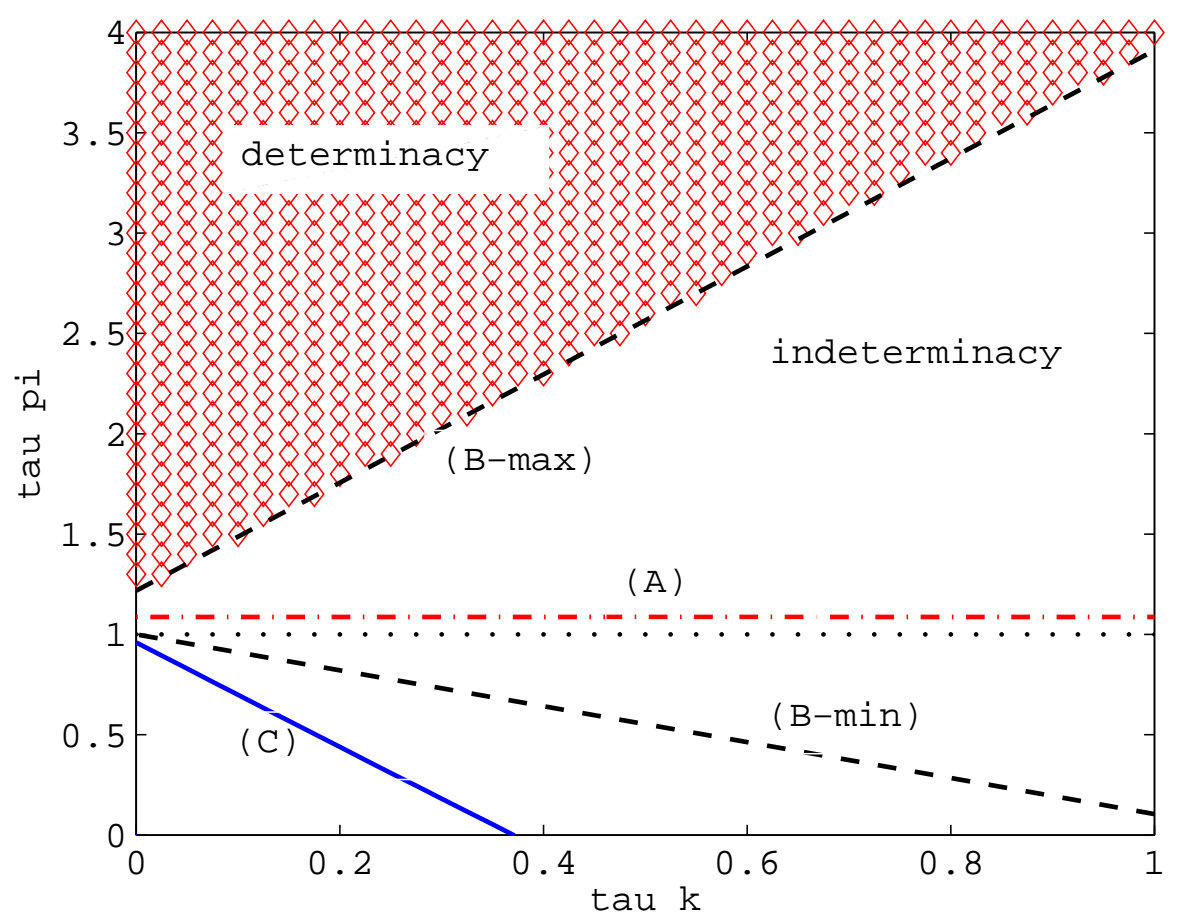

Notes: In the region with red diamonds, equilibrium is determinate, and in other regions, indeterminate. The vertical axis denotes the central bank's response to inflation $\tau_{\pi}$. The horizontal axis denotes the central bank's response to the capital price $\tau_{k}$. Other parameters are $\sigma=1, \gamma=0, \alpha=0.3, \beta=.99$, $\lambda=0.019, Z=0.85$, and $\varphi=0.02$. 
Figure 2: Effect of monetary policy on the determinacy region (2)

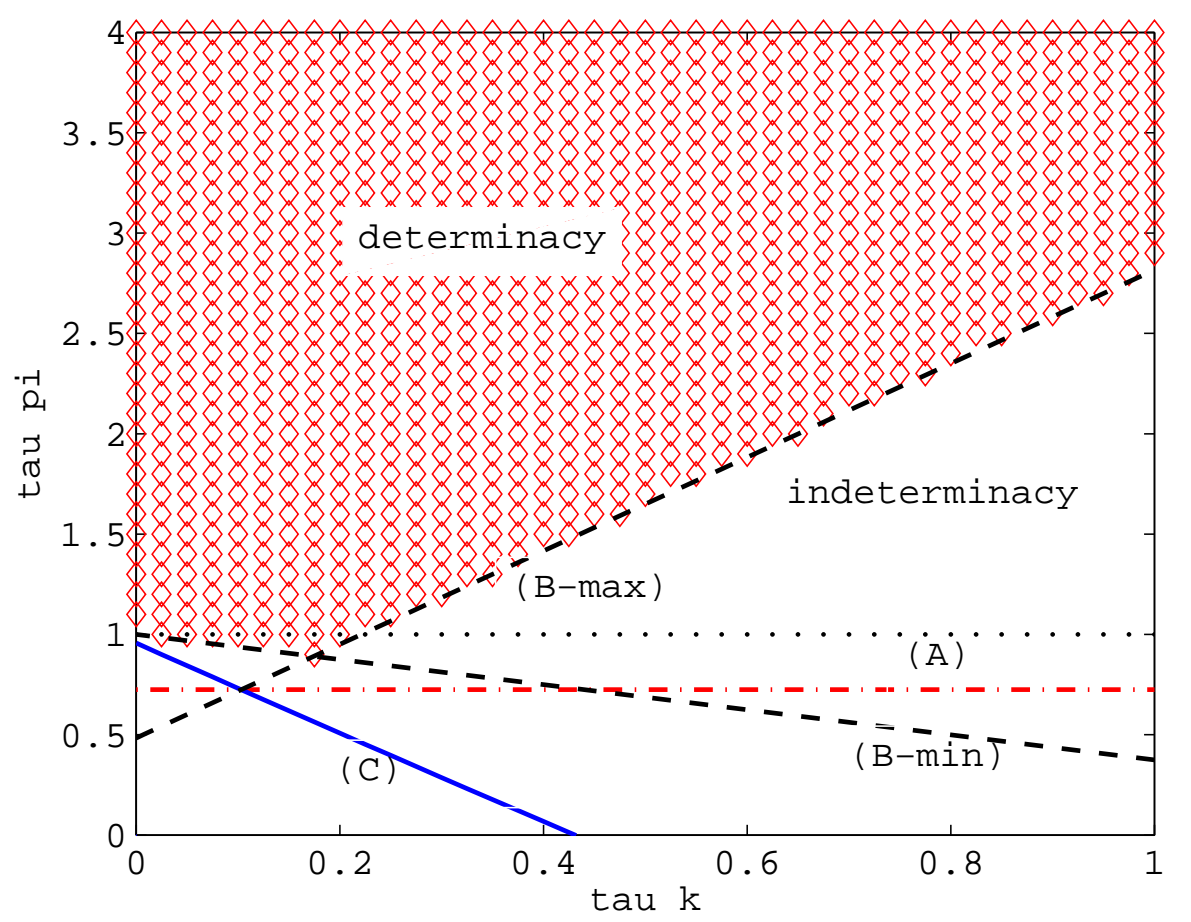

Notes: In the region with red diamonds, equilibrium is determinate, and in other regions, indeterminate. The vertical axis denotes the central bank's response to inflation $\tau_{\pi}$. The horizontal axis denotes the central bank's response to the capital price $\tau_{k}$. Other parameters are $\sigma=2, \gamma=2, \alpha=0.3, \beta=.99$, $\lambda=0.019, Z=0.85$, and $\varphi=0.02$. 
Figure 3: Effect of credit market imperfections on the determinacy region (1)

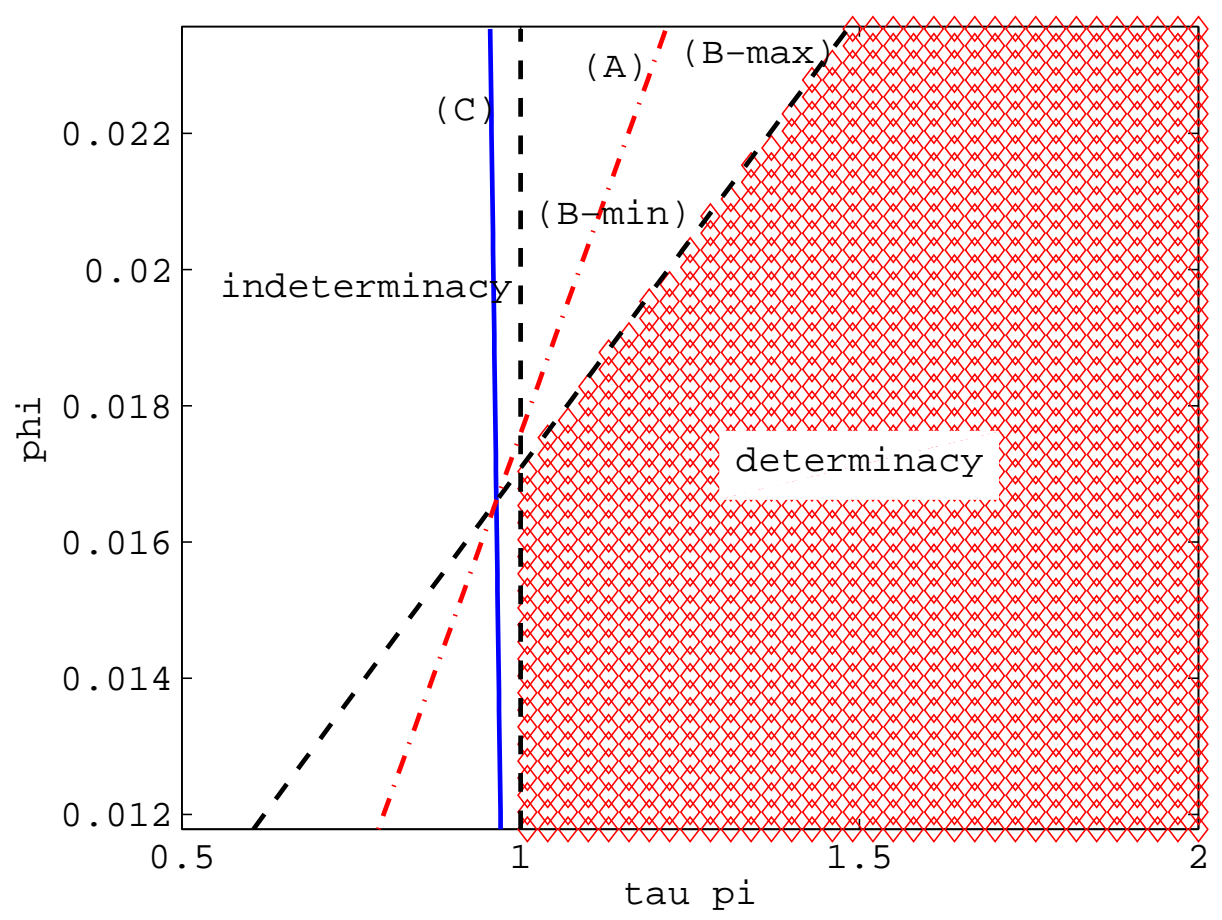

Notes: In the region with red diamonds, equilibrium is determinate, and in other regions, indeterminate. The vertical axis denotes the collateral constraint parameter $\varphi$. The horizontal axis denotes the central bank's response to inflation $\tau_{\pi}$. Other parameters are $\sigma=1, \gamma=0, \alpha=0.3, \beta=.99$, $\lambda=0.019, Z=0.85$, and $\tau_{k}=0$. 
Figure 4: Effect of credit market imperfections on the determinacy region (2)

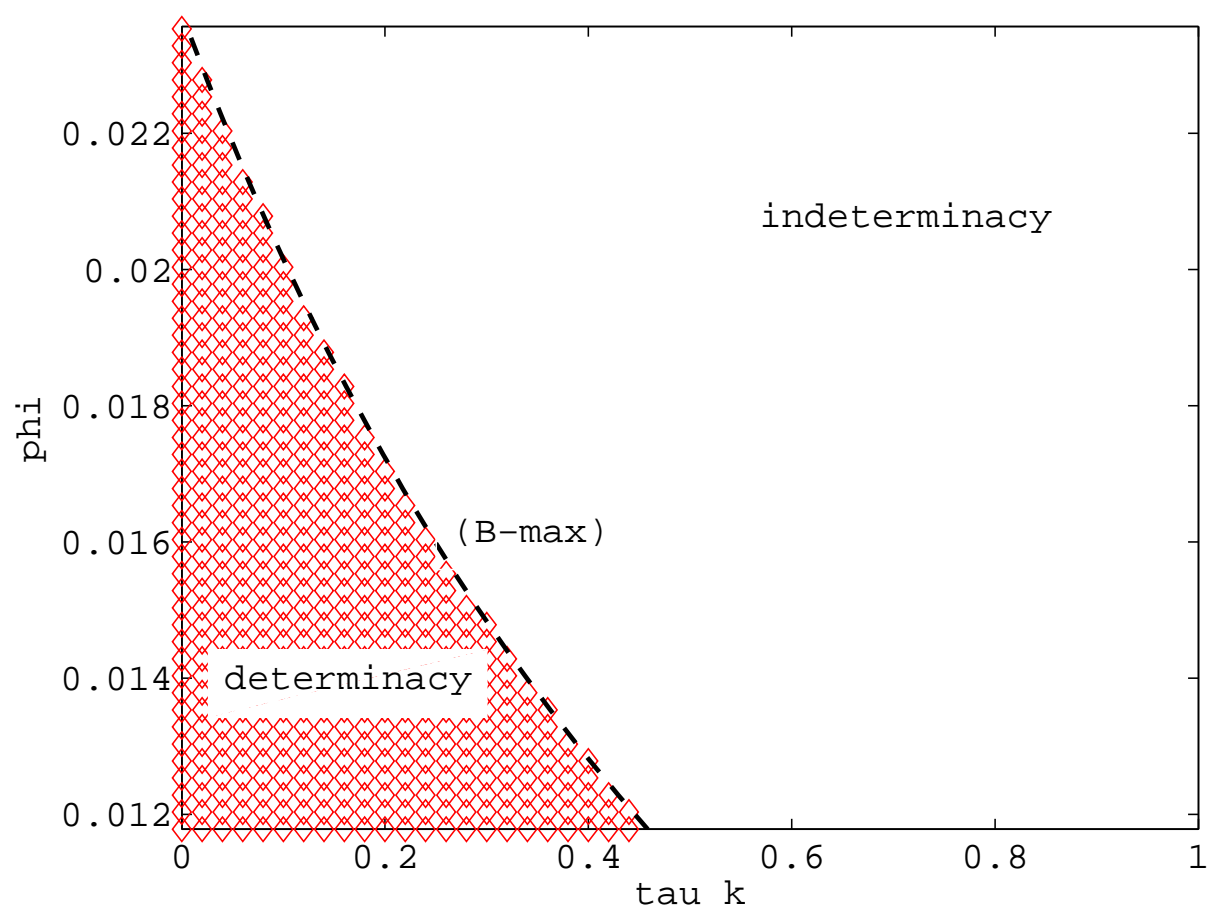

Notes: In the region with red diamonds, equilibrium is determinate, and in other regions, indeterminate. The vertical axis denotes the collateral constraint parameter $\varphi$. The horizontal axis denotes the central bank's response to the capital price $\tau_{k}$. Other parameters are $\sigma=1, \gamma=0, \alpha=0.3, \beta=.99$, $\lambda=0.019, Z=0.85$, and $\tau_{\pi}=1.5$. 
Figure 5: Effect of monetary policy on the determinacy region (3): Variation of capital stock

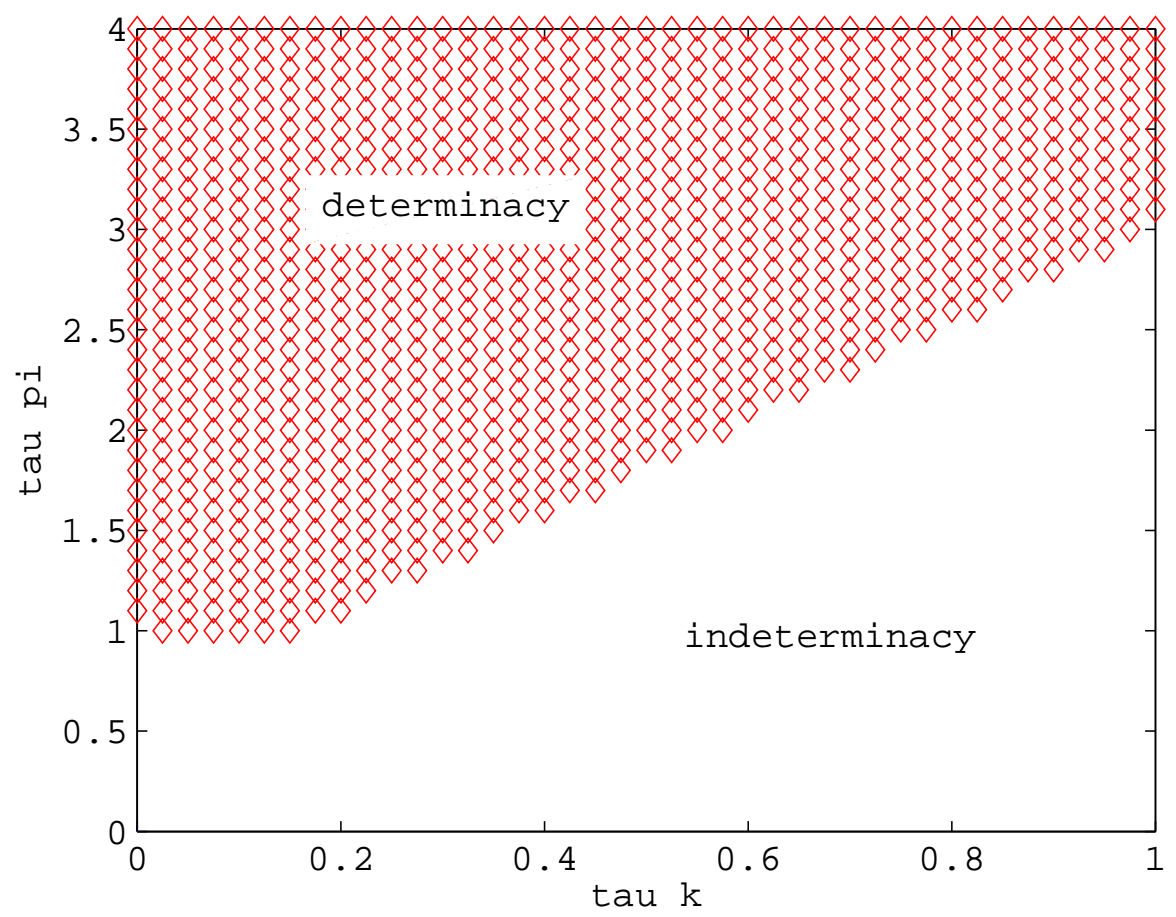

Notes: In the region with red diamonds, equilibrium is determinate, and in other regions, indeterminate. The vertical axis denotes the central bank's response to inflation $\tau_{\pi}$. The horizontal axis denotes the central bank's response to the capital price $\tau_{k}$. Other parameters are $\sigma=1, \gamma=0, \alpha=0.3, \beta=.99$, $\lambda=0.019, Z=0.85, \delta=0.025, \eta=0.5$, and $\varphi=0.02$. 
Figure 6: Effect of credit market imperfections on the determinacy region (3): Variation of capital stock

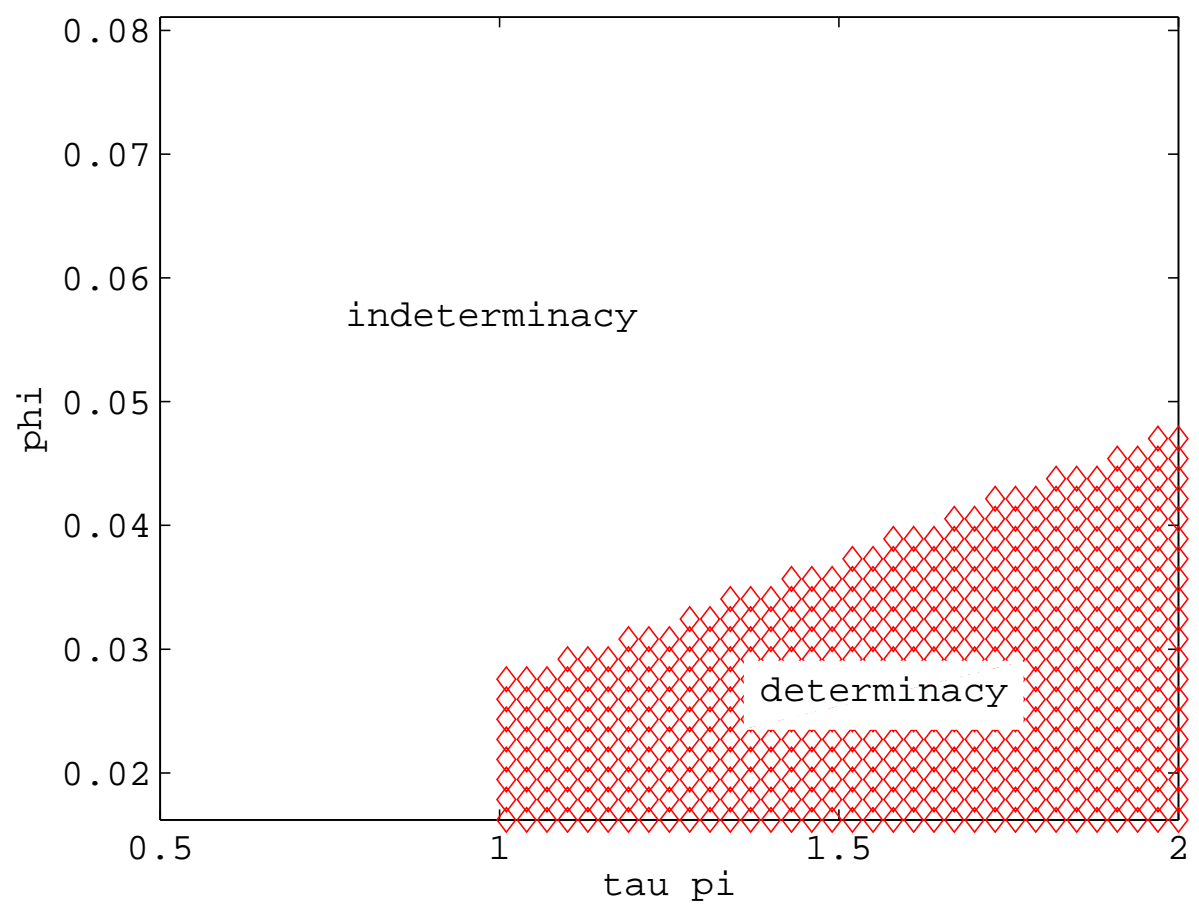

Notes: In the region with red diamonds, equilibrium is determinate, and in other regions, indeterminate. The vertical axis denotes the collateral constraint parameter $\varphi$. The horizontal axis denotes the central bank's response to inflation $\tau_{\pi}$. Other parameters are $\sigma=1, \gamma=0, \alpha=0.3, \beta=.99$, $\lambda=0.019, Z=0.85, \delta=0.025, \eta=0.5$, and $\tau_{k}=0$. 
Figure 7: Effect of credit market imperfections on the determinacy region (4): Variation of capital stock

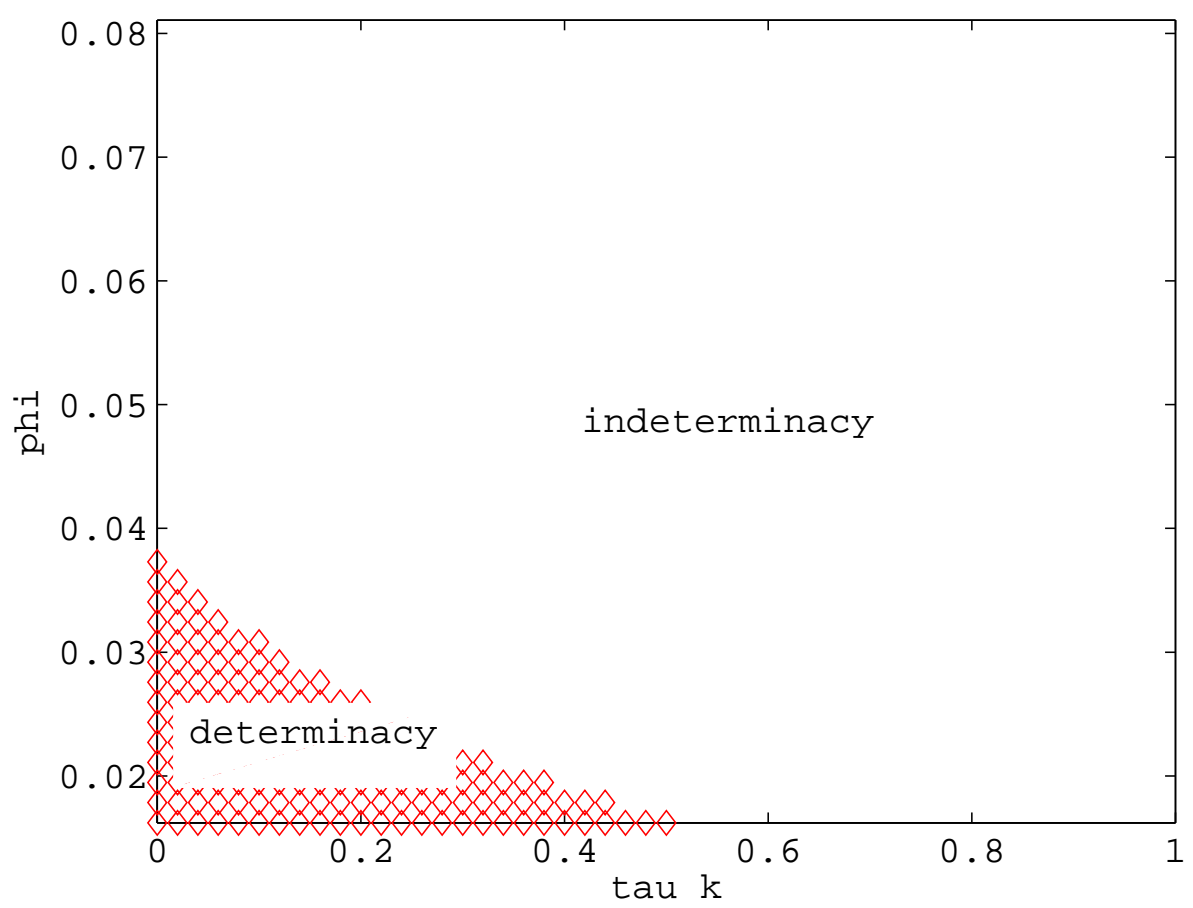

Notes: In the region with red diamonds, equilibrium is determinate, and in other regions, indeterminate. The vertical axis denotes the collateral constraint parameter $\varphi$. The horizontal axis denotes the central bank's response to the capital price $\tau_{k}$. Other parameters are $\sigma=1, \gamma=0, \alpha=0.3, \beta=.99$, $\lambda=0.019, Z=0.85, \delta=0.025, \eta=0.5$, and $\tau_{\pi}=1.5$. 